\title{
Expression of a defective mouse mammary tumor virus envelope glycoprotein precursor which binds stably to GRP78 within the lumen of the endoplasmic reticulum is associated with decreased glucocorticoid-induced apoptosis in mouse lymphoma cells
}

\author{
Minh Lam ${ }^{1}$, Michael Stallcup ${ }^{2}$ and Clark W. Distelhorst ${ }^{1,3}$ \\ ${ }^{1}$ Department of Medicine, Case Western Reserve University, Cleveland, Ohio, \\ USA \\ 2 Departments of Pathology and Biochemistry, University of Southern California \\ Health Sciences Center, Los Angeles, California 90033, USA \\ ${ }^{3}$ corresponding author: Dr Clark W. Distelhorst, Department of Medicine, \\ School of Medicine (BRB 329), Case Western Reserve University, 10900 Euclid \\ Avenue, Cleveland, Ohio 44106-4937, USA. tel: 216-368-1175; \\ fax: 216-368-1166; e-mail: cwd@po.cwru.edu
}

Received 10.11.96; revised 9.1.97; accepted 11.1.97

Edited by B.A. Osborne

\begin{abstract}
Viral proteins inhibit apoptosis in host cells by a variety of mechanisms. This report proposes an additional mechanism, based on the interaction of a mutant mouse mammary tumor virus (MMTV) envelope glycoprotein precursor, Pr74, with the stress protein GRP78 (BiP) within the lumen of the endoplasmic reticulum (ER) (J. Biol. Chem. 268 7482-7488, 1993). We show that WEHI7.2 (W7.2) mouse lymphoma cells, which do not express Pr74, are more sensitive to cell death induction by the glucocorticoid hormone dexamethasone (dex), than W7MG1 cells, which were derived by infecting W7.2 cells with MMTV and therefore express Pr74 under control of the glucocorticoid-inducible MMTV promoter. Moreover, W7ENV/N cells, derived by stably transfecting W7.2 cells with a constitutively expressed cDNA encoding mutant Pr74, were less sensitive to dex-induced cell death than control transfectant W7-ENV/- cells. Among multiple W7-ENV/N subclones, susceptibility to dex-induced cell death was inversely related to the level of Pr74 synthesis. The interaction of Pr74 with GRP78 induces an increase in GRP78 synthesis. Thus, the repression of cell death associated with Pr74 expression may be secondary to elevated synthesis of GRP78, a stress protein previously implicated in protection against cell death.
\end{abstract}

Keywords: apoptosis; GRP78; mouse mammary tumor virus; viral envelope glycoprotein precursor

Abbreviations: ICE, interleukin- $1 \beta$ converting enzyme; EBV, Esptein Barr virus; iap, inhibitor of apoptosis gene; MMTV, mouse mammary tumor virus; GRP78, $78 \mathrm{kDa}$ glucose regulated protein; $\mathrm{ER}$, endoplasmic reticulum; dex, dexamethasone; W7.2, WEHI7.2

\section{Introduction}

The decision of a cell to undergo apoptosis, or programmed cell death, can be initiated by a variety of intracellular and extracellular signals. Once initiated, the process of apoptosis is regulated by a genetically conserved array of counterbalancing factors, including proteins such as $\mathrm{Bcl}-2$ that inhibit apoptosis, and proteases, such as homologues of interleukin $1 \beta$-converting enzyme (ICE), that mediate cleavage of specific target proteins (Steller, 1995; White, 1996). Cell death by apoptosis is important for normal development and homeostasis, and serves as a mechanism by which individual cells eliminate themselves for the overall good of the organism.

In lymphocytes and other types of cells apoptosis can be triggered by viruses, including, for example, human immunodeficiency virus-type 1 (Li et al, 1995; Maldarelli et al, 1995; Westendorp et al, 1995), human T lymphocyte virus 1 (Leno et al, 1995), adenovirus (Chiou et al, 1994), and varicella-zoster virus (Sadzot-Delvaux et al, 1995). The host apoptotic response contributes to the cytopathic effect of viruses, but also provides protection against viral infection by limiting viral replication (Clem and Miller, 1993). However, many viruses subvert the host defense mechanism by encoding proteins that inhibit apoptosis, thereby facilitating viral replication, spread, or persistance (Shen and Shenk, 1995). A number of anti-apoptotic viral proteins have been identified that inhibit apoptosis by various mechanisms. For example, Cowpox virus crmA protein and baculovirus p35 protein inhibit ICE and ICE-like proteases, respectively (Tewari and Dixit, 1995; Clem and Miller, 1993; Hershberger et al, 1994). The Epstein-Barr virus (EBV) LMP1 protein upregulates Bcl-2 expression (Okan et al, 1995), whereas the EBV BHRF-1 protein is a member of the Bcl-2 family of proteins and appears to inhibit apoptosis by a mechanism similar to $\mathrm{Bcl}-2$ (Henderson et al, 1993). Other members of the Bcl-2 family include the adenovirus E1B $19 \mathrm{~K}$ protein and a Bcl-2 homologue encoded by the African Swine Fever virus (Chiou et al, 1994; Neilan et al, 1993). Finally, an antiapoptotic protein encoded by the baculovirus inhibitor of apoptosis (iap) gene contains a zinc finger motif and presumably acts as a transcription factor (Birnbaum et al, 1994).

In the present report, we propose an additional mechanism by which a naturally occurring mutant viral protein may inhibit apoptosis, involving interaction of the viral protein with GRP78 (BiP), a stress protein implicated in protection against cell death (Little and Lee, 1994). Two previously characterized derivatives of the glucocorticoid- 
sensitive WEHI7.2 (W7.2) T cell mouse lymphoma line, W7.MG1 and W7-ENV/N, are employed in this study. W7.MG1 cells were derived by infecting W7.2 cells with mouse mammary tumor virus (MMTV) (Danielsen et al, 1983) and express a mutant MMTV envelope glycoprotein precursor Pr74 that is not processed normally, but retained within the ER (Byravan and Stallcup, 1990). W7-ENV/N cells were derived from W7.2 cells by retroviral mediated transfer of a sequence encoding the mutant, nonprocessed form of Pr74 (Bedgood et al, 1992; Corey and Stallcup, 1992). In an earlier study, we found that mutant Pr74 expressed in both W7.MG1 and W7-ENV/N cells binds stably to GRP78 within the lumen of the endoplasmic reticulum (ER), thereby inducing an increase in GRP78 synthesis (Ulatowski et al, 1993). Because elevated levels of GRP78 have been correlated with resistance to apoptosis (Shen et al, 1987; Hughes et al, 1989; Sugawara et al, 1990; Li and Lee, 1991; Gomer et al, 1991; Li et al, 1992), the present studies were undertaken to determine if expression of mutant Pr74 in W7.2 mouse lymphoma cells is associated with reduced sensitivity of lymphoma cells to glucocorticoid-induced apoptosis.

\section{Results}

The W7.2 and W7.MG1 lines, like all BALB/C mouse derived cell lines, contain MMTV sequences stably integrated within the genome (Horibata and Harris, 1970). Therefore, to determine the expression level of the MMTV glycoprotein precursor, Pr74, dex-treated and untreated cells were labeled with $\left[{ }^{35}\right.$ S]methionine and Pr74 was immunoprecipitated from cell extracts (Figure 1). These findings indicate that Pr74 expression was not detected in W7.2 cells, whereas both basal and dex-inducible expression of Pr74 were detected in W7MG1 cells. To determine if Pr74 expression affects cell survival, cells were treated with a range of concentrations of dex, followed by assessment of viability (i.e. trypan blue dye exclusion) at periodic time intervals. Comparison of the death response in W7.2 cells versus W7MG1 cells over a broad range of dex concentrations showed W7MG1 cells to be significantly less susceptible to dex-induced cell death (Figure 2). Cell death following dex treatment of W7.2 and W7MG1 cells is associated with nuclear morphological changes typical of apoptosis (Lam et al, 1993, 1994). Consistent with the data shown in Figure 2, apoptotic morphological changes induced by dex were much more frequent in W7.2 cells than in

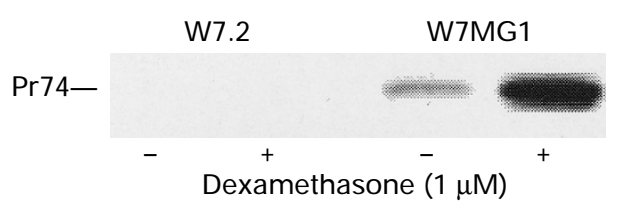

Figure 1 Differential expression of Pr74 in W7.2 and W7MG1 cells. Cells were incubated with or without $1 \mu \mathrm{M}$ dex for $4 \mathrm{~h}$ and then pulse-labeled with $\left[{ }^{35}\right.$ S]methionine. Pr74 was immunoprecipitated from cell extracts containing equivalent amounts of trichloroacetic acid precipitable radioactivity and subjected to SDS-gel electrophoresis, followed by autoradiography. Shown is an autoradiogram representative of multiple experiments.
W7MG1 cells (data not shown). Thus, the data in Figure 2 are consistent with the hypothesis that expression of mutant Pr74 inhibits apoptosis induction.

One of the earliest detectable events in cells destined to die in response to glucocorticoid treatment is a generalized repression of protein synthesis (Borthwick, 1978). To determine the effect of Pr74 expression on the repression of protein synthesis by dex, W7.2 and W7.MG1 cells were pretreated with dex for $4 \mathrm{~h}$ prior to measuring the incorporation of $\left[{ }^{35}\right.$ S $]$ methionine into newly synthesized protein (Table 1). A significant decrease in $\left[{ }^{35}\right.$ S]methionine
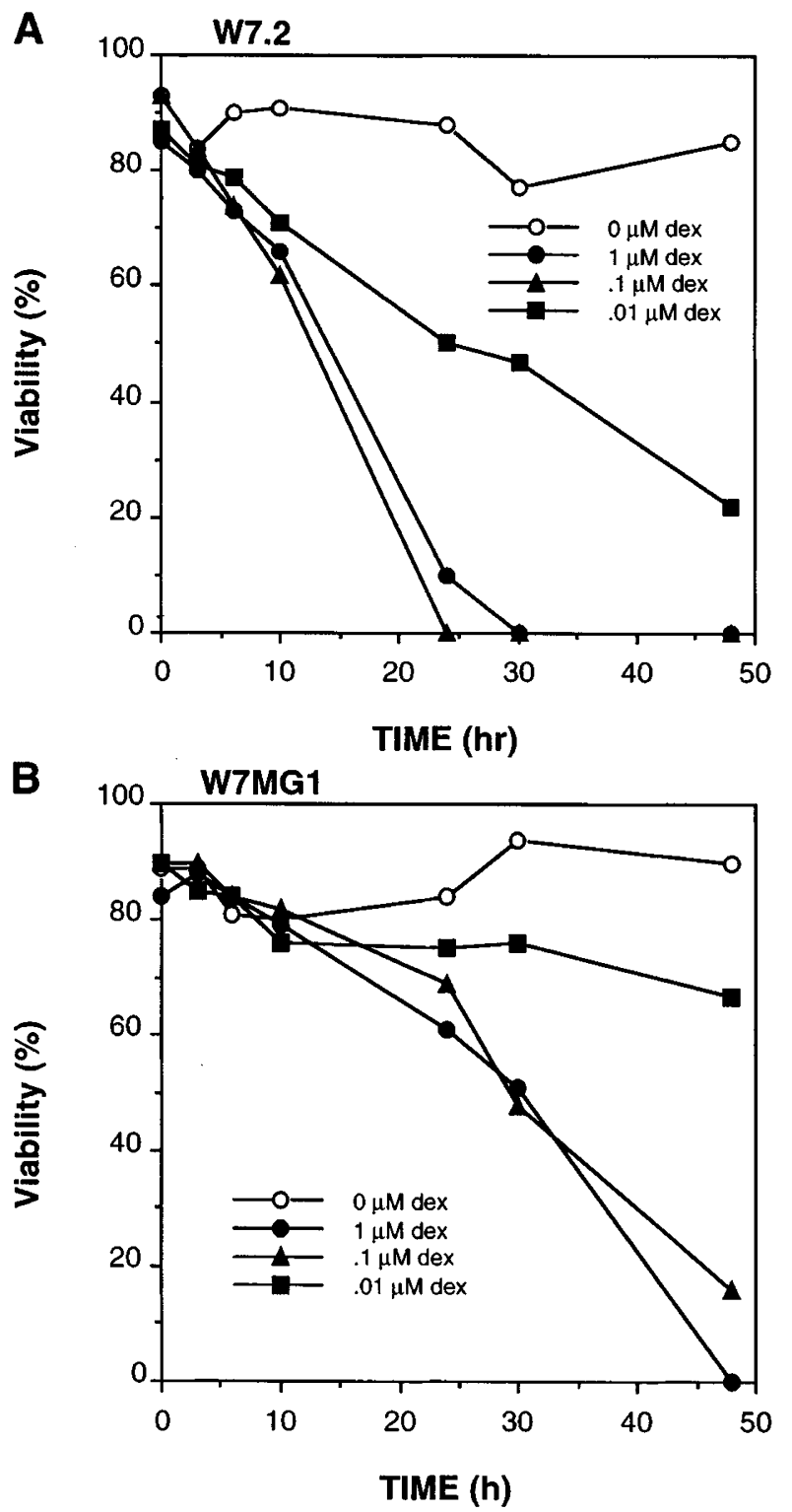

Figure 2 Effect of dex on viability of W7.2 and W7MG1 cells. Cells were cultured with or without $0.01-1 \mu \mathrm{M}$ dex and, at various time points, cell viability was measured by trypan blue dye exclusion. Symbols are the mean of duplicate determinations for a single experiment that is representative of five experiments. 
incorporation was detected in W7.2 cells but not in W7MG1 cells following dex treatment. These data confirm that dex has a greater catabolic effect in W7.2 cells than in W7GM1 cells. One factor known to regulate the sensitivity of lymphoid cells to glucocorticoids is glucocorticoid receptor content (Vanderbilt et al, 1987). W7.2 and W7MG1 cells have similar glucocorticoid receptor levels (Table 2).

Table 1 Effect of dexamethasone treatment on protein synthesis

\begin{tabular}{lcccc}
\hline dex & W7.2 & W7MG1 & W7ENVI- & W7-ENV/N \\
\hline & {$\left[{ }^{35}\right.$ S $]$ methionine incorporation (cpm/million cells) } \\
- & 149800 & 167600 & 491300 & 509300 \\
& \pm 8500 & \pm 12500 & \pm 16400 & \pm 200 \\
+ & 99800 & 159500 & 379000 & 512800 \\
& \pm 18000 & \pm 21500 & \pm 6500 & \pm 12200 \\
$\pm \times 100$ & $66 \%$ & $95 \%$ & $77 \%$ & $100 \%$ \\
\hline
\end{tabular}

Cells were incubated with or without $1 \mu \mathrm{M}$ dexamethasone (dex) for $4 \mathrm{~h}$ prior to pulse-labeling with ${ }^{35}$ S $]$ methionine. The incorporation of ${ }^{35}$ S $]$ methionine into protein was quantified by measuring trichlroacetic acid precipitable radioactivity. Results represent the mean \pm S.E. for four separate experiments.

Table 2 Glucocorticoid receptor levels

\begin{tabular}{lc}
\hline Cell line & Specific binding \\
\hline & dpm/40 million cells (mean \pm S.E.) \\
W7.2 & $22090 \pm 1898$ \\
W7MG1 & $16129 \pm 4153$ \\
W7-ENV/- & $15534 \pm 1118$ \\
W7-ENV/N & $17884 \pm 413$ \\
\hline
\end{tabular}

The specific binding of $\left.{ }^{3} \mathrm{H}\right]$ triamcinolone was measured by a standard whole cell competitive binding assay in which cells were incubated with a concentration of $\left[{ }^{3} \mathrm{H}\right]$ triamcinolone sufficient to saturate receptor sites, in the presence or absence of 100 -fold excess unlabeled hormone.
Therefore, the differential sensitivity to glucocorticoids does not lie at the glucocorticoid receptor level.

The preceding findings suggest that Pr74 expression may protect cells against the catabolic action of glucocorticoids. To test this hypothesis, we compared the dex sensitivity of two additional W7.2 derivatives, W7-ENV/N and $\mathrm{W} 7-\mathrm{ENV} /-$, prepared by stable transfection of W7.2 cells with a retroviral vector encoding Pr74 or an empty retroviral vector respectively (Bedgood et al, 1992). We showed previously that W7-ENV/N cells constitutively express defective Pr74 and that nascent Pr74 accumulates within the ER in stable association with GRP78 (Ulatowski et al, 1993). Here we show that W7-ENV/N cells were less sensitive than W7-ENV/ - cells to dex-induced repression of protein synthesis (Table 1) and cell death (Figure 3). The difference in dex sensitivity was not regulated at the level of the glucocorticoid receptor, as W7-ENV/N and W7-ENV/cells have the same intracellular concentration of glucocorticoid receptors (Table 2). Analysis of multiple W7-ENV/ $\mathrm{N}$ subclones reveals an inverse relationship between the level of Pr74 synthesis and sensitivity to dex-induced cell death (Figure 4). These data confirm that increased expression of mutant Pr74 is associated with decreased sensitivity to dex-induced cell death.

\section{Discussion}

Viruses subvert the apoptotic program of mammalian cells by a variety of mechanisms (Shen and Shenk, 1995). The observations reported here suggest an additional mechanism, involving synthesis of a naturally occurring, defective viral protein that accumulates within the ER in stable association with GRP78. The evidence is based on an inverse correlation between the level of expression of a defective MMTV

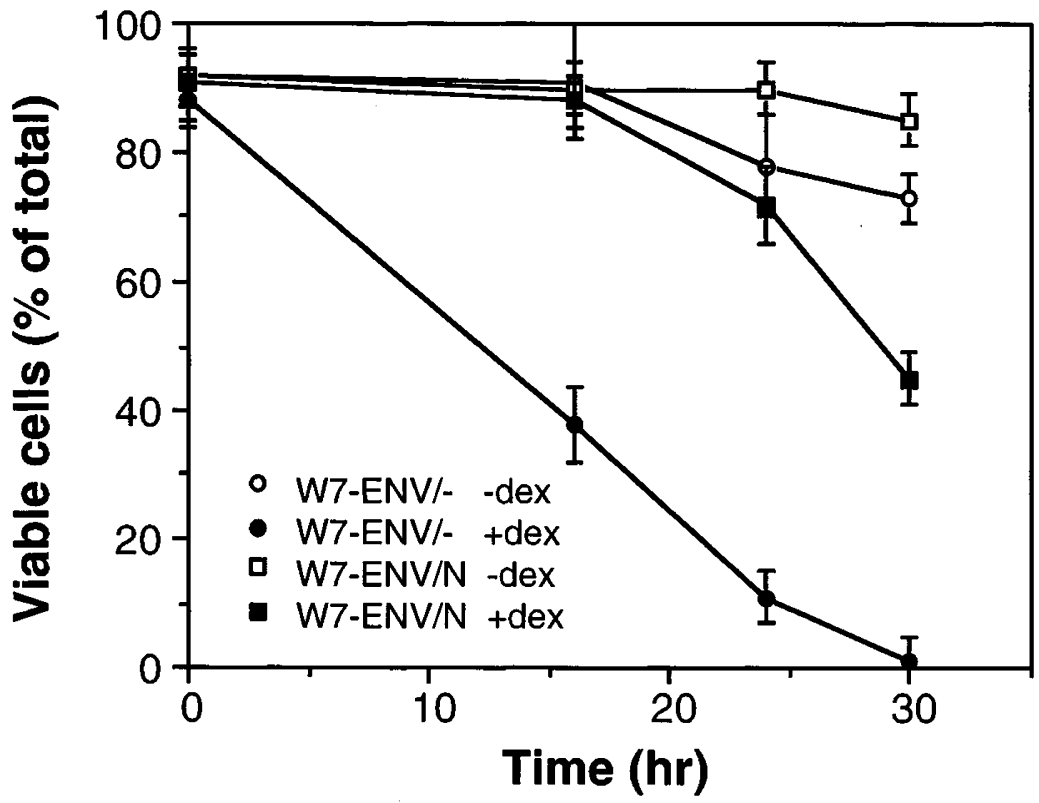

Figure 3 Effect of dex on viability of W7-ENV/ - and W7-ENV/N cells. Cells were cultured with or without $1 \mu \mathrm{M}$ dex and cell viability was measured at various times by Trypan blue dye exclusion. Symbols are the mean \pm S.E. of three experiments. 


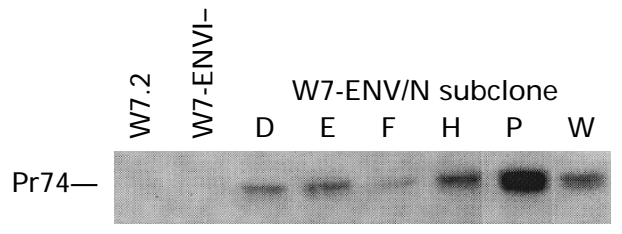

B

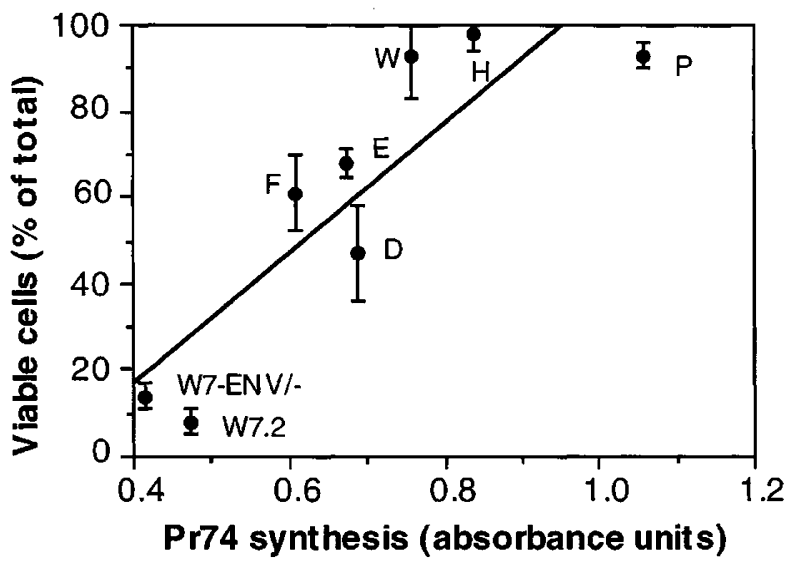

Figure 4 Relationship between dex-induced cell death and levels of nascent Pr74. (A) W7.2 cells, W7-ENV/ - cells and W7-ENV/N subclones were pulse labeled with $\left[{ }^{35} \mathrm{~S}\right]$ methionine and then Pr74 was immunoprecipitated from cell extracts containing equivalent amounts of tricholoacetic acid precipitable radioactivity. Immunoprecipitated proteins were subjected to SDS-PAGE, followed by autoradiography. (B) Cells were incubated for $24 \mathrm{~h}$ in the presence or absence of $1 \mu \mathrm{M}$ dex prior to measuring cell viability by Trypan blue dye exclusion. Relative levels of nascent Pr74 were determined by scanning densitometry of the autoradiogram shown in $(\mathbf{A})$ and plotted versus cell viability. Symbols represent mean \pm S.E. cell viability in three experiments.

envelope glycoprotein precursor, Pr74, and the susceptibility of lymphoid cells to glucocorticoid-induced apoptosis. How the stable interaction between Pr74 and GRP78 reduces the susceptibility of mouse lymphoma cells to glucocorticoidinduced apoptosis is currently unknown. One possibility is that protection against apoptosis is mediated through elevated synthesis of GRP78, which occurs secondary to the stable interaction between Pr74 and GRP78 within the ER lumen. Indeed, we reported previously a direct relationship between levels of defective Pr74 synthesis and GRP78 synthesis (Ulatowski et al, 1993).

GRP78 (BiP) is a highly conserved $78 \mathrm{kDa}$ protein that resides within the ER lumen (Munro and Pelham, 1986; Hendershot et al, 1988). GRP78 has a high degree of amino acid sequence homology to the $70 \mathrm{kDa}$ heat shock protein (HSP70) and is, therefore, considered a member of the HSP70 family of stress proteins (Hunt and Morimoto, 1985). GRP78 functions as a molecular chaperone, associating transiently with nascent proteins, facilitating their translocation into the ER (Sanders et al, 1992) and aiding in their folding and assembly into oligomeric structures (Bole et al, 1986; Dorner et al, 1987). For example, in B lymphocytes, nascent immunoglobulin heavy chains and light chains associate with GRP78 until they assemble to form complete immunoglobulin molecules (Haas and Wabl, 1983). Thus, like other members of the HSP70 family GRP78 is thought to function as a catalyst of protein assembly, binding and hydrolyzing ATP as it associates and dissociates from peptides and proteins (Flynn et al, 1989; Gething and Sambrook, 1992). Normal polypeptides bind only transiently to GRP78 (Olden et al, 1979; Welch et al, 1983). However, abnormal proteins, such as Pr74 in the present study, bind irreversibly to GRP78, causing their retention within the ER and inducing an elevation in the level of GRP78 synthesis (Bole et al, 1986; Dorner et al, 1987; Kassenbrock et al, 1988; Hendershot et al, 1988; Kozutsumi et al, 1988).

Cells that express high levels of GRP78 resist the repression of protein synthesis that results from depletion of ER-associated calcium stores by calcium ionophore treatment (Brostrom et al, 1990, Brostrom and Brostrom, 1990). Moreover, induction of GRP78 synthesis by anoxia, calcium mobilization by the calcium ionophore $A 23187$, or inhibition of protein glycosylation by 2-deoxyglucose or tunicamycin impedes the cell death response to a variety of apoptosis inducers, including calcium mobilizing agents (Li and Lee, 1991; Li, 1992), oxidative stress (Gomer, 1991), cytotoxic T cells (Sugawara et al, 1990), tumor necrosis factor (Sugawara et al, 1990), and a number of cytotoxic agents (Shen and Shenk, 1987; Hughes et al, 1989). Indeed, abrogation of the GRP78 stress response increases the cytotoxic response to calcium mobilizing agents ( $\mathrm{Li}$ and Lee, 1991; Li et al, 1992; Little and Lee, 1995) and cell mediated cytotoxicity (Sugawara et al, 1993).

The mechanism by which elevated GRP78 synthesis maintains cell survival is unknown. A major function of the $\mathrm{ER}$ is to sequester and release calcium for use in intracellular signaling (Carafoli, 1987). Moreover, the ER calcium pool is essential for a number of vital cellular functions which include protein processing (Lodish, 1992; Gething, 1992), maintaining high translation rates of newly transcribed messages (Brostrom et al, 1990, Brostrom and Brostrom, 1990), preserving the structural integrity of the ER (Koch et al, 1988; Booth and Koch, 1989), and regulating cell proliferation and cell cycle progression (Short et al, 1993). In a previous report, we showed that viral protein-mediated induction of GRP78 synthesis is accompanied by decreased calcium efflux out of the ER lumen following inhibition of ER-associated calciumATPase activity by thapsigargin (Lam et al, 1993). Thus, it is possible that elevated levels of GRP78 may maintain cell viability by interfering with intracellular calcium signals involved in mediating apoptosis or by maintaining ER functions necessary for cell survival.

The defective MMTV envelope glycoprotein Pr74 that binds stably to GRP78 is only one of several viral proteins reported to bind stably to GRP78 within the ER lumen. For example, a misfolded influenza virus hemagglutinin (Hurtley et $a l, 1989)$ and a vesicular stomatitis virus $G$ protein (Machamer et al, 1990) bind stably to GRP78. Moreover, infection of cells with paramyxoviruses stimulates synthesis of GRP78 (Peluso et al, 1978). Expression of these viral proteins is not associated with cell death, but effects on cell survival following apoptotic signals have not been investigated. Thus, the possibility exists that a range of viruses may regulate cell death by expressing proteins that interact with GRP78 and thereby induced GRP78 synthesis. 


\section{Materials and Methods}

\section{Materials}

Acrylamide and other chemicals for gel electrophoresis were from BioRad. Molecular weight standards were from Pharmcia LKB Biotechnology. Dexamethasone (dex) and other chemicals were from Sigma. $\left[{ }^{35}\right.$ S]methionine $(1100 \mathrm{Ci} / \mathrm{mmol})$ was from ICN.

\section{Cell lines and cell culture}

W7.2 is a T cell line derived from a BALB/c mouse lymphoma (Horibata and Harris, 1970). W7MG1 cells were derived by infecting W7.2 cells with MMTV (Danielsen et al, 1983). W7-ENV/N cells were derived from W7.2 cells by retroviral mediated transfer of a sequence encoding a defective form of Pr74 that is not processed normally, but retained within the ER (Bedgood et al, 1992; Corey and Stallcup, 1992). W7ENV/ - cells were prepared by infecting W7.2 cells with the empty retroviral vector. Multiple subclones of the W7-ENV/N line were derived by a limiting dilution technique described previously (Reid, 1979). Cells were maintained in complete medium (Dulbecco's Modified Eagle's Medium supplemented with $2 \mathrm{mM}$ glutamine, 50 units $/ \mathrm{ml}$ penicillin, $50 \mu \mathrm{g} / \mathrm{ml}$ streptomycin, $0.4 \mathrm{mM}$ non-essential amino acids, and $10 \%(\mathrm{v} / \mathrm{v})$ heat inactivated horse serum) at $37^{\circ} \mathrm{C}$ in a $7 \%$ $\mathrm{CO}_{2}$ atmosphere and diluted into fresh medium three times per week to maintain a maximum cell density below 1.5 million cells $/ \mathrm{ml}$.

\section{Cell viability}

Cell viability was assessed by light microscopy after suspension in trypan blue dye. Cells that excluded trypan blue dye were considered viable.

\section{Cell treatment and labeling}

Dex, dissolved in ethanol and diluted into complete medium, was added to cells to give final concentrations ranging from $0.01 \mu \mathrm{M}$ to $1 \mu \mathrm{M}$; an equivalent amount of ethanol in complete medium was added to untreated cells. Cells were then incubated at $37^{\circ} \mathrm{C}$ prior to labeling with $\left[{ }^{35} S\right]$ methionine. For labeling, cells were gently pelleted and resuspended in complete medium lacking methionine; $\left[{ }^{35}\right.$ S]methionine was then added to give a final concentration of $50 \mu \mathrm{Ci} / \mathrm{ml}$ and the cells were incubated for an additional $30 \mathrm{~min}$ at $37^{\circ} \mathrm{C}$.

\section{Immune precipitation}

Methods of cytosol preparation, and immune precipitation were previously described in detail (Ulatowski et al, 1993). After treatment with dex and labeling with $\left[{ }^{35} \mathrm{~S}\right]$ methionine as described above, cells were lysed by resuspension and incubation for $15 \mathrm{~min}$ at $4^{\circ} \mathrm{C}$ in the following buffer: $50 \mathrm{mM}$ Tris, $\mathrm{pH} 7.4,150 \mathrm{mM} \mathrm{NaCl}, 10 \mathrm{mM}$ iodoacetamide, $1 \%$ Triton X-100. Cell extracts were centrifuged at $14000 \times g$ for $20 \mathrm{~min}$ at $4^{\circ} \mathrm{C}$ and the concentration of radiolabeled protein in the clear supernatant cytosol was measured by tricholoracetic acid precipitation. Cytosol samples containing equivalent amounts of radiolabeled protein were incubated for $60 \mathrm{~min}$ at $4{ }^{\circ} \mathrm{C}$ with a rabbit polyclonal antibody to Pr74 (Corey, 1992), or an equivalent concentration of a control IgG (Sigma). Immunoreactive proteins were adsorbed to goat anti-mouse IgG-agarose, analyzed by SDS-polyacrylamide gel electrophoresis and exposed to Kodak XAR-5 film at $-80^{\circ} \mathrm{C}$.

\section{Receptor assay}

The number of glucocorticoid receptors per cell was measured by a previously described whole cell competitive binding assay (Distelhorst et al, 1984).

\section{Acknowledgement}

This work was supported by Public Health Service grant CA-42755 from the National Cancer Institute.

\section{References}

Bedgood RM, Bahner I, Kohn DB and Stallcup MR (1992) Two different genes coding for processable and non-processable forms of a viral envelope protein can account for the apparent hormonal stimulation of protein processing in W7MG1 lymphoma cells. Mol. Endo. 6: 459-467

Birnbaum MJ, Chen RJ and Miller LK (1994) An apoptosis-inhibiting gene from a nuclear polyhedrosis virus encoding a polypeptide with $\mathrm{Cys} / \mathrm{His}$ sequence motifs. J. Virol. 68: 2521-2528

Bole DG, Hendershot LM and Kearney JF (1986) Post-translational association of immunoglobulin heavy chain binding protein with nascent heavy chains in nonsecreting and secreting hybridomas. J. Cell Biol. 102: 1558-1566

Booth C and Koch GLE (1989) Perturbation of cellular calcium induces secretion of luminal ER proteins. Cell 59: $729-737$

Borthwick NM (1978) Regulation of macromolecular synthesis by glucocorticoids in rat thymus. In Glucocorticoid action and leukemia, Bell PA and Borthwick NM, eds (Cardiff: Alpha Omega Publishing Limited) pp. 41-52

Brostrom CO and Brostrom MA (1990) Calcium-dependent regulation of protein synthesis in intact mammalian cells. Annu. Rev. Physiol. 52: 577-590

Brostrom MA, Cade C, Prostko CR, Gmitter-Yellen D and Brostrom CO (1990) Accomodation of protein synthesis to chronic deprivation of intracellular sequestered calcium: A putative role for GRP78. J. Biol. Chem. 265: 2053920546

Byravan S and Stallcup MR (1990) Glucocorticoid-dependent maturation of mouse mammary tumor virus glycoproteins in mouse lymphoma cells: Isolation of variants with constitutive viral protein maturation and normal glucocorticoid receptor function. Mol. Endo. 4: 341-348

Carafoli E (1987) Intracellular calcium homeostasis. Ann. Rev. Biochem. 56: 395 433

Chiou SK, Tseng CC, Rao L and White E (1994) Functional complementation of the adenovirus EiB 19-kilodalton protein with Bcl-2 in the inhibition of apoptosis in infected cells. J. Virol. 68: 6553-6566

Clem RJ and Miller LK (1993) Apoptosis reduces both the in vitro replication and the in vivo infectivity of a baculovirus. J. Virol. 67 : $3730-3738$

Corey JL and Stallcup MR (1992) The effect of glucocorticoid on the subcellular localization, oligomerization, and processing of mouse mammary tumor virus envelope protein precursor Pr74. Mol. Endo. 6: 450-458

Danielsen M, Peterson DO and Stallcup MR (1983) Immunological selection of variant mouse lymphoid cells with altered glucocorticoid responsiveness. Mol. Cell. Biol. 3: 1310-1316

Distelhorst CW, Benutto BM and Bergamini RA (1984) Effect of cell cycle position on dexamethasone binding by mouse and human lymphoid cell lines: correlation between an increase in dexamethasone binding during $S$ phase and dexamethasone sensitivity. Blood 63: 105-113

Dorner AJ, Bole DG and Kaufman RJ (1987) The relationship of N-linked glycosylation and heavy chain-binding protein association with the secretion of glycoproteins. J. Cell Biol. 105: 2665-2674

Flynn GC, Chappell TG and Rothman JE (1989) Peptide binding and release by proteins implicated as catalysts of protein assembly. Science 245 : $385-390$

Gething M-J and Sambrook J (1992) Protein folding in the cell. Nature 355: 33-45

Gomer CJ, Ferrario A, Rucker N, Wong S and Lee AS (1991) Glucose regulated protein induction and cellular resistance to oxidative stress mediated by porphyrin photosensitization. Cancer Res. 51: 6574-6579

Haas IG and Wabl M (1983) Immunoglobulin heavy chain binding protein. Nature 306: $387-389$ 
Hendershot LM, Ting J and Lee AS (1988) Identity of the immunoglobulin heavychain-binding protein with the 78,000-dalton glucose-regulated protein and the role of posttranslational modifications in its binding function. Mol. Cell. Biol. 8: $4250-4256$

Henderson S, Huen D, Rowe M, Dawson C, Johnson G and Rickinson A (1993) Epstein-Barr virus-coded BHRF-1 protein, a viral homologue of Bcl-2, protects human B cells from programmed cell death. Proc. Natl. Acad. Sci. USA 90: $8479-8483$

Hershberger PA, LaCountDJ and Friesen PD (1994) The apoptotic suppressorp53 is required early during baculovirus replication and is targeted to the cytosol of infected cells. J. Virol. 68: 3467-3477

Horibata K and Harris AW (1970) Mouse myelomas and lymphomas in culture. Exp. Cell Res. 60: 61-77

Hughes CS, Shen JW and Subjeck JR (1989) Resistance to etoposide induced by three glucose-regulated stresses in Chinese hamster ovary cells. Cancer Res. 49: $4452-4454$

Hunt C and Morimoto RI (1985) Conserved features of eukaryotic HSP70 genes revealed by comparison with the nucleotide sequence of human HSP70. Proc. Natl. Acad. Sci. USA 82: 6455-6459

Hurtley SM, Bole DG, Hoover-Litty H, Helenius A and Copeland CS (1989) Interactions of misfolded influenza virus hemagglutinin with binding protein (BiP). J. Cell Biol. 108: 2117-2126

Kassenbrock CK, Garcia PD, Walter P and Kelley RB (1988) Heavy-chain binding protein recognizes aberrant polypeptides translocated in vitro. Nature 333: $90-$ 93

Koch GLE, Booth C and Wooding FBP (1988) Dissociation and reassembly of the endoplasmic reticulum in live cells. J. Cell Science 91: $511-522$

Kozutsumi Y, Segal M, Normington K, Gething M-J and Sambrook J (1988) The presence of malfolded proteins in the endoplasmic reticulum signals the induction of glucose-regulated proteins. Nature 332: 462-464

Lam M, Dubyak G, Chen L, Nuñez G, Miesfeld RL and Distelhorst CW (1994) Evidence that $B C L-2$ represses apoptosis by regulating endoplasmic reticulumassociated Ca2+ fluxes. Proc. Natl. Acad. Sci. USA 91: 6569-6573

Lam M, Dubyak G and Distelhorst CW (1993) Effect of glucocorticoid treatment on intracellular calcium homoestasis in mouse lymphoma cells. Mol. Endo. 7:686693

Leno M, Simpson RM, Bowers FS and Kindt TJ (1995) Human T lymphocyte virus 1 from a leukemogenic cell lines mediates in vivo and in vitro lymphocyte apoptosis. J. Exp. Med. 181: 1575-1580

Li CJ, Friedman DJ, Wang C, Metelev V and Pardee AB (1995) Induction of apoptosis in uninfected lymphocytes by HIV-1 Tat protein. Science 268: 429-431

Li L-J, Li X, Ferrario A, Rucker N, Liu ES, Wong S, Gomer CJ and Lee AS (1992) Establishment of a chinese hamster ovary cell line that expresses grp78 antisense transcripts and suppresses A23187 induction of both GRP78 and GRP94. J. Cell. Physiol. 153: 575-582

Li X and Lee AS (1991) Competitive inhibition of a set of endoplasmic reticulum protein genes (GRP78, GRP94, and ERp72) retards cell growth and lowers viability after ionophore treatment. Mol. Cell Biol. 11: 3446-3453

Little E and Lee AS (1995) Generation of a mammalian cell line deficient in glucoseregulated protein stress induction through targeted ribozyme driven by a stress inducible promoter. J. Biol. Chem. 270: 9526 -9534

Little E, Ramakrishnan M, Roy B, Gazit G and Lee AS (1994) The glucose-regulated proteins (GRP78 and GRP94): Functions, gene regulation, and applications. Crit. Rev. Eukaryotic Gene Express. 4: 1-18

Lodish HF, Kong N and Wikstrom L (1992) Calcium is required for folding of newly made subunits of the asialoglycoprotein receptor within the endoplasmic reticulum. J. Biol. Chem. 267: 12753-12760

Machamer CE, Doms RW, Bole DG, Helenius A and Rose JK (1990) Heavy chain binding protein recognizes incompletely disulfide-bonded forms of vesicular stomatitis virus G protein. J. Biol. Chem. 265: 6879-6883
MaldarelliF Sato H, BertholdE Orenstein J and Martin MA (1995) Rapid induction of apoptosis by cell-to-cell transmission of human immunodeficiency virus type 1. J. Virol. 69: 6457-6465

Munro S and Pelham HRB (1986) An hsp70-like protein in the ER: Identity with the $78 \mathrm{kd}$ glucose-regulated protein and immunoglobulin heavy chain binding protein. Cell 46: $291-300$

Neilan JG, Lu Z, Afonso CL, Kutish GF, Sussman MD and Rock DL (1993) An African swine fever virus gene with similarity to the proto-oncogene bcl-2 and the Epstein-Barr virus gene BHRF-1. J. Virol. 67: 4391-4394

Okan J, Wang Y, Chen F, Hu LF, Imreh S, Klein G and Wiman KG (1995) The EBVencoded LMP1 protein inhibits p53-triggered apoptosis but not growth arrest. Oncogene 11: 1027-1301

Olden K, Pratt RM, Jaworski C and Yamamda KM (1979) Evidence for role of glycoprotein carbohydrates in membrane transport: specific inhibition by tunicamycin. Proc. Natl. Acad. Sci. 76: 791-795

Peluso RW, Lamb RA and Choppin PW (1978) Infection with paramyxoviruses stimulates synthesis of cellular polypeptides that are also stimulated in cells transformed by Rous sarcoma virus or deprived of glucose. Proc. Natl. Acad. Sci. USA 75: 6120-6124

Reid LCM (1979) Cloning. Meth. Enzymol. 58: 152-164

Sadzot-Delvaux C, Thonard P, Schoonbroodt S, Piette J and Rentier B (1995) Varicella-zoster virus induces apoptosis in cell culture. Journal of General Virology 76: 2875-2879

Sanders SL, Whitfield KM, Vogel JP, Rose MD and Schekman RW (1992) Sec61p and BiP directly facilitate polypeptide translocation into the ER. Cell 69:353-365

Shen J, Hughes C, Chao C, Cai J, Bartels C, Gessner T and Subjeck J (1987) Coinduction of glucose-related proteins and doxorubicin resistance in Chinese hamster cells. Proc. Natl. Acad. Sci. 84: 3278-3282

Shen Y and Shenk TE (1995) Viruses and apoptosis. Current Opinion in Genetics and Develop. 5: 105-111

Short AD, Bian J, Ghosh TK, Waldron RT and Rybak SL (1993) Intracellular Ca2+ pool content is linked to control of cell growth. Proc. Natl. Acad. Sci. USA 90: $4986-4990$

Steller H (1995) Mechanisms and genes of cellular suicide. Science 267: $1445-$ 1449

Sugawara S, Nowicki M, Xie S, Song H-J and Dennert G (1990) Effects of stress on lysability of tumor targets by cytotoxic $\mathrm{T}$ cells and tumor necrosis factor. $\mathrm{J}$. Immunol. 145: 1991-1998

Sugawara S, Takeda K, Lee A and Dennert G (1993) Suppression of stress protein GRP78 induction in tumor B/C10ME eliminates resistance to cell mediated cytotoxicity. Cancer Res. 53: 6001-6005

Tewari M and Dixit VM (1995) Fas- and tumor necrosis factor-induced apoptosis is inhibited by the poxvirus crmA gene product. J. Biol. Chem. 270: 3255-3260

Ulatowski LM, Lam M Vanderburg G, Stallcup MR and Distelhorst CW (1993) Relationship between defective mouse mammary tumor virus envelope glycoprotein synthesis and GRP78 synthesis in glucocorticoid-treated mouse lymphoma cells: Evidence for translational control of GRP78 synthesis. J. Biol. Chem. 268: 7482-7488

Vanderbilt JN, Miesfeld R, Maler BA and Yamamoto KR (1987) Intracellular receptor concentration limits glucocorticoid-dependent enhancer activity. Mol. Endo. 1: $68-74$

Welch WJ, Garrels JI, Thomas PG, Lin JJC and Feramisco JR (1983) Biochemical characterization of the mammalian stress proteins and identification of two stress proteins as glucose- and Ca2+-ionophore-regulated proteins. J. Biol. Chem. 258: $7102-7111$

Westendorp MO, Frank R, Ochsenbauer C, Stricker K, Dhein J, Walczak H, Debatin KM and Krammer PH (1995) Sensitization of T cells to CD95-mediated apoptosis by HIV-1 Tat and gp120. Nature 375: 497-500

White E (1996) Life, death, and the pursuit of apoptosis. Genes and Develop. 10: 1 - 